\title{
Pheochromocytoma - An Institutional Experience
}

\author{
R SHENOY G RODRIGUES V JAIN SAKHAN \\ Department Of General Surgery: Kasturba Medical College Manipal, Karnataka, India \\ Correspondence to Dr: Giabriel Rodrigues, MS. DNB. Associate Professor of Surgery. Manipal Karnataka, India. Email: rodricksgabvlayahoo.co.in
}

\begin{abstract}
Objective: The present study envisages evaluating the clinical presentation, diagnosis, management, with particular reference to pharmacological and anesthetic considerations, and outcome in patients with pheochromocytoma. Design: A retrospective study. Place and Duration of Study: The study was conducted at the Department of Surgery, Kasturba Medical College Hospital, Manipal, India from January 1, 1996 to December 31, 2003. Patients and Methods: Seventeen patients diagnosed to have pheochromocytoma were included for this study. Our assessment of age at presentation, sex, presenting complaints with details of hypertension (HT), diagnostic tests, surgical procedure and follow-up was based on patient records. Results: Peak incidence was observed in 40-50 years age group, with male preponderance. All the patients had diastolic HT of more than $100 \mathrm{~mm}$ of $\mathrm{Hg}$ at presentation. Systolic blood pressures (SBP) were between $150 \mathrm{~mm} \mathrm{Hg}$ to $230 \mathrm{~mm} \mathrm{Hg}$, with mean of $170 \mathrm{~mm} \mathrm{Hg}$; nine patients presented with persistent HT and seven had paroxysmal HT. One patient infact presented with hypotension due to septic shock and was incidentally detected to have an adrenal tumor. Computed tomography (CT) scan and urinary levels of vanillylmandelic acid (VMA) were mainstay of diagnosis. These patients had adequate preoperative control of HT. All patients underwent exploration of the tumor by an extraperitoneal approach. $70 \%$ tumors were on the right and $30 \%$ were on the left side. Histopathologically, all the tumors were benign except for one, which was malignant. An average of three to five units of blood transfusion was required and mean operating time was 4.5 hours. Six patients had extensive intra-operative blood pressure (BP) fluctuation, but were adequately managed by the anesthetic team. One patient with post-operative pulmonary edema died in our series; rest all the patients are on regular follow-up, till date and doing well. Conclusion: Pheochromocytoma is an important cause of endocrine HT. Elevated urinary VMA is diagnostic of this tumor with imaging studies used to localize the tumor. Adrenalectomy results in complete cure of HT with an excellent long-term outcome.
\end{abstract}

Key words: Pheochromocytoma, proxysmal hypertension, urinary vanillylmandelic acid, catecholamines, adrenalectomy.

Pheochromocytomas are rare tumors that occur in young and middle aged patients, with equal frequency in males and females. ${ }^{\prime}$ Most of these arise in the adrenal gland and only $10 \%$ are extra-adrenal in origin. This tumor is a causative factor of HT in less than $1 \%$ of hypertensive population, however detection is mandatory, not only for potential of cure of the HT, but also to avoid the potentially lethal effects of the unrecognized tumor, due to the paroxysmal HT it produces. ${ }^{2}$ Literature is replete with case reports of pheochromocytoma diagnosed at postmortem in patients who have died during or after a surgical procedure. ${ }^{3,4}$ Due to the widespread use of ultrasonography (USG) and CT scan $^{5}$ diagnosis of pheochromocytoma has become easy in suspected cases. With adequate pre-operative preparation ${ }^{6}$, good surgical technique, careful and judicious anesthesia with intraoperative monitoring and post-operative care ${ }^{7}$ mortality rates have come down to less than $1 \%$. We present our experience of 17 cases of pheochromocytoma.

\section{Patients and methods:}

This is a retrospective study where in medical records of nineteen patients with histopathologically verified diagnosis of pheochromocytoma between January 1, 1996 and December 31, 2003, admitted in Kasturba Medical College Hospital, Manipal, India were analyzed. Two patients with incomplete records were excluded from the study. Hospital records of these patients were reviewed for demographic data, modes of presentation with details of
HT, diagnostic modalities and surgical procedure including peri-operative drug therapy and anesthetic management, were analyzed. These patients are being followed up actively thereafter, till date.

\section{Results:}

Among these 17 patients, 11 were male. The age at presentation varied between 17 - 53 years, with peak incidence in the 40-50 age group (12 patients) and the remaining three patients were in the age group of 30-40 years (Table 1). Thirteen patients were symptomatic for less than 6 months, three had symptoms for almost a year and one patient had relatively recent onset of symptoms, of less than one-month duration.

Table I: Age at presentation

\begin{tabular}{ll}
\hline Age group (years) & No. of patients \\
\hline$<30$ & 1 \\
$30-40$ & 3 \\
$40-50$ & 12 \\
$>50$ & 1 \\
\hline
\end{tabular}

All patients had diastolic HT of more than $100 \mathrm{~mm}$ of $\mathrm{Hg}$ at the time of admission, except for one with hypotension and septic shock, with a mean of $105 \mathrm{~mm}$ of $\mathrm{Hg}$. Two patients had diastolic blood pressure of $150 \mathrm{~mm}$ of $\mathrm{Hg}$, associated with blackout. SBP varied between 150 and $230 \mathrm{~mm}$ of $\mathrm{Hg}$ (mean $=170 \mathrm{~mm}$ of $\mathrm{Hg}$ ). Persistent HT was observed in nine patients, of which 3 had superimposed paroxysms. "Dramatic attacks" (paroxysms) alone were seen in 7 
patients. All female patients experienced paroxysms at some point of time during the course of their illness, four experienced paroxysms alone and two paroxysms superimposed on persistent HT (Table II).

Table II: Patterns of hypertension

\begin{tabular}{lll}
\hline Pattern & Males & Females \\
\hline Persistent HT only & 6 & None \\
$\begin{array}{l}\text { Persistent HT with superimposed } \\
\text { paroxysms }\end{array}$ & 1 & 2 \\
Paroxysmal HT alone & 3 & 4 \\
\hline
\end{tabular}

Paroxysmal attack was associated with palpitations in 5 patients [50\%], sweating in 5 patients $(50 \%)$, chest pain in 2 patients $(20 \%)$, and black out in $2(20 \%)$ patients. Interestingly, one patient had paroxysms on brushing the teeth. Five patients presented to the hospital due to the severe headache more in the occipital region and were diagnosed to have HT due to pheochromocytoma. One patient had severe itching all over the body and was found to have HT, which on further investigations proved to be due to pheochromocytoma. Four patients presented with abdominal pain in the right hypochondrium with vomiting and later they were diagnosed to have pheochromocytoma. One patient presented to the hospital with hypotension and septic shock due to pneumonia. Incidental abdominal ultrasound scan in this patient detected an adrenal tumor and further enquiry, he admitted revealed having palpitation and anxiety disorder for the last 6 months and was on treatment. Four patients $(24 \%)$ were diagnosed to have diabetes of more than 6 months duration when they were referred to us. None of the patients had cerebrovascular accident but one had convulsions (Table III).

Table III: Associated symptoms

\begin{tabular}{ll}
\hline Symptoms & No. of patients \\
\hline Palpitations & 5 \\
Headache & 5 \\
Sweating & 5 \\
Abdominal pain & 4 \\
Chest pain & 2 \\
Black outs & 2 \\
Itching & 1 \\
Convulsions & 1 \\
\hline
\end{tabular}

Fifteen patients were referred to us with diagnosed HT and USG evidence of an adrenal tumor. These were reconfirmed by CT scan, which showed calcification in 3 and central necrosis in 4 patients. In one patient, the diagnosis of pheochromocytoma was made by VMA levels, but localization could not be done by USG and CT scan. Hence she was subjected to a metaiodobenzylguanidine (MIBG) scan that revealed a right adrenal tumor. VMA levels in 24-hour urine sample were elevated in all these patients ranging from 7.9 to $39.5 \mathrm{mg} \%$ with an average of $15.5 \mathrm{mg} \%$. The levels of the VMA did not correspond to the severity of the symptoms.
All these patients were hospitalized for the definitive treatment. Adequate control of the HT was achieved by alpha-adrenergic blocking agent, Phenoxybenzamine $10 \mathrm{mg}$ thrice a day. Atenolol $25 \mathrm{mg}$ OD along with phenoxybenzamine was administered to 5 patients for adequate control of hypertension. In three patients Propranolol 20mg BD was added to control tachycardia. These drugs were given for 15 days prior to the surgical procedure.

All patients underwent exploration and adrenalectomy by an extraperitoneal, thoracoabdominal route, incision being placed at the bed of the $10^{\text {th }}$ rib. Twelve $(70 \%)$ tumors were on the right side and five $(30 \%)$ were on the left side. In one case, the tumor was found to be adherent to the diaphragm on the right side. As it clinically seemed to be malignant, a cuff of the diaphragm was excised along with the tumor. Histopathology later confirmed this to be malignant. An average of 3.5 units of blood transfusion was required with minimum of 2 and maximum of 8 units. Operating time, which included anesthesia time, ranged from 3 hours 45 minutes to 8 hours with the mean of 4.5 hours.

Intra-operative monitoring included electrocardiography (ECG) in V5 and lead II, BP both invasive and right atrial, central venous pressure (CVP) by right internal jugular vein, nasopharyngeal temperature, fingerprobe pulse oximetry, capnography and urine output. In 6 patients, large fluctuations of BP were recorded intraoperatively which was controlled with phentolamine (4 patients) and sodium nitroprusside (2 patients). Postoperatively, all patients were managed in ICU. Fifteen patients were shifted to the ward within 34 hours of the surgery. One patient with malignant pheochromocytoma required 5 days of ICU admission. One patient developed pulmonary edema and significant edema of the head and neck. This patient required dopamine and adrenaline to maintain $\mathrm{BP}$ in the post-operative period. She also developed hypocalcemia resulting in carpopedal spasm, which did responded to intravenous calcium gluconate initially, but succumbed. This was the only death in our series.

All patients are being actively followed up till date. Cure of HT has been achieved in all patients. Repeat USG done after a gap of one year does not show evidence of any recurrence or other pheochromocytoma. Three of the four diabetics were cured of the disease as blood sugar reports were within normal limits, however one patient is on oral hypoglycemic agents with reasonably good control of diabetes.

\section{Discussion:}

Pheochromocytoma is an uncommon endocrine neoplasm and is an important cause of surgically correctable/curable $\mathrm{HT}^{8}$. The present study is a small study of this uncommon neoplasm involving 17 patients. Ninety percent of these tumors are solitary ${ }^{8}$, as in our series. Less than $10 \%$ of 
pheochromocytomas are extra-adrenal, multiple and malignant ${ }^{8.9}$. Though our series did not have any extraadrenal and/or multiple neoplasms, there was one malignant pheochromocytoma.

Pheochromocytoma is known to occur in certain familial syndromes. These include Multiple Endocrine Neoplasia (MEN) 2A and 2B, neurofibromatosis (von Recklinghausen disease) and von Hippel-Lindau (VHL) disease. ${ }^{10.11}$ Pheochromocytoma can occur bilaterally in the MEN syndromes in as many as $70 \%$ of cases and they tend to be extra-adrenal ${ }^{11}$.

Fifteen $(88 \%)$ patients in our series were in the age group of 30-50 years, which correlates well with available statistics, ${ }^{8,9}$ even though pheochromocytomas can be found in all ages. These tumors occur with equal frequency in males and females ${ }^{8,9}$, however in the present series male to female ratio is $2: 1$.

HT is the most common manifestation, which is paroxysmal in $50 \%$ of cases. ${ }^{2,4,12}$ Sixteen (95\%) patients in our series presented with HT, which was paroxysmal in 10 patients. One patient had hypotension; secretion of the hypotensive adrenomedullin may contribute to the hypotension in some patients. One patient had severe itching and found to have HT; this may be explained by the vasodilatation due to the hypermetabolic state of the patient. Four patients were found to have raised blood glucose levels, possibly due to adrenaline excess and in three patients it was completely cured after removal of the tumor.

Elevated level of 24-hour urine VMA confirms the diagnosis, however VMA is not very specific, with a false positive rate of greater than $15 \%$. Metanephrines are considered the most sensitive and specific for pheochromocytoma; two recent studies demonstrated that plasma metanephrine levels are sensitive in detecting pheochromocytomas ${ }^{13,14}$. For now, however, it is not widely available commercially in this country. VMA levels were elevated in all our patients.

Localization of the tumor was a difficult task before the days of USG and CT $\operatorname{scan}^{15,16}$. Modlin ${ }^{16}$ et al published a series of 72 patients with pheochromocytoma between 1955-1976. They used various methods to localize these tumors like intravenous urography, presacral insufflation, selective arteriography, and selective venous sampling. Today these tests are obsolete due to the availability of USG and CT scan. Abdominal CT scan has an accuracy of $85-95 \%$ in detecting adrenal masses with a spatial resolution of $1 \mathrm{~cm}$ or greater. However, it is less accurate for lesions smaller than $1 \mathrm{~cm}^{15}$. Again differentiating an adenoma from a pheochromocytoma is difficult using CT scan. Magnetic resonance imaging (MRI) is preferred over CT scan $^{1.16,17}$ in detecting small and extra-adrenal tumors. MRI has a sensitivity of $100 \%$ in detecting adrenal pheochromocytomas, does not necessitate contrast, and does not expose the patient to ionizing radiation. We do not advocate routine use of MRI for localization of these tumors unless indicated, due to its wide unavailability and the cost factor.

A MIBG scan is reserved for cases when a pheochromocytoma is confirmed biochemically but CT scan or MRI fail to visualize a tumor ${ }^{8,17,18}$. The molecular structure of iodine - $123\left({ }^{123} \mathrm{I}\right)$ used for this scan resembles norepinephrine and concentrates within adrenal or extraadrenal pheochromocytomas. This isotope has a short half-life and is very expensive. It frequently is utilized in cases of familial pheochromocytoma syndromes, recurrent or malignant pheochromocytoma.

Surgical resection of the tumor is the treatment of choice and usually results in cure of the hypertension ${ }^{18}$ as in all our patients. Careful treatment with alpha and betablockers is required ${ }^{19}$ pre-operatively to control BP and prevent intra-operative hypertensive crises. Bravo $^{20}$ et al recommend alpha blockade with phenoxybenzamine 7-10 days pre-operatively to allow for expansion of blood volume, volume expansion with isotonic sodium chloride, initiation of a beta blocker only after adequate alpha blockade. If beta blockade is started prematurely, unopposed alpha stimulation can precipitate a hypertensive crisis. All our patients received alpha-blockers till the morning of surgery, but only five patients required betablockers.

Both experienced anesthesiologist and surgeon are crucial to the success of the operation. Surgical mortality rates are less than $2-3 \%$ with an experienced anesthesiologist and surgeon ${ }^{19,20}$. Management of anesthesia for patients requiring excision of pheochromocytoma is based on the administration of drugs which do not stimulate the sympathetic nervous system plus the use of invasive monitoring techniques to facilitate early and appropriate intervention when catecholamine induced changes in the cardiovascular system occur. ${ }^{21,22}$ These changes are more likely to occur during tracheal intubation, during manipulation of the tumor, and after ligation of the tumors venous drainage ${ }^{23}$.

Induction of anesthesia is most often accomplished with intravenous administration of a barbiturate, etomidate or propofol ${ }^{21,22}$. Our anesthesiologist preferred propofol for rapid induction. The depth of anesthesia is increased and maintained by nitrous oxide plus a volatile agent, like isoflurane ${ }^{22}$ at most centers' including ours. Nitroprusside or phentolamine must be readily available for administration should gross fluctuation of blood pressure occur intraoperatively ${ }^{22,24}$ as had happened in six of our patients. Blood should be available for infusion to replace intraoperative loss as well as to fill the dilated vascular tree after tumor is removed.

Adrenalectomy, by open anterior, posterior or thoracoabdominal approaches or by laparoscopy, completely cures hypertension in majority of cases. Anterior approach to right adrenal requires a long right subcostal incision with patient positioned supine. Left adrenal similarly is exposed through a long left subcostal 
incision; both extraperitoneal and intraperitoneal exploration is possible through subcostal incision. In our series all the patients underwent exploration of the tumor by extraperitoneal route. Posterior approach to adrenals requires incision along the twelfth rib with patient placed prone on two chest rolls. Irrespective of the approach used, the important technical points to be taken care of are to avoid disturbing the tumor excessively. The adrenal vein should be identified and ligated as early in the operation as possible to prevent excessive release of catecolamines ${ }^{25}$.

Recently, laparoscopic adrenalectomy has become the procedure of choice for well-localized pheochromocytomas. Open surgery is reserved for extraadrenal tumors, large tumors or cases in which malignancy is suspected ${ }^{26}$. Laparoscopic adrenalectomy, like open procedure, can be done by transperitoneal, retroperitoneal (anterior or lateral) approaches. Most laparoscopic surgeons, however, prefer transperitoneal approach, and retroperitoneal approach is kept reserved for patients who have undergone previous abdominal surgery, or when bilateral adrenalectomy is required as the patient does not require to be repositioned, thereby reducing anesthesia time $e^{172}$

Invasive monitoring is continued in the immediate post-operative period, as fluctuation in BP is likely. Patient should be best treated in the ICU under the supervision of critical care specialist. Persistent hypotension, which was seen in one of our patient, refractory to intravascular fluid volume replacement is the principal post-operative complication. This hypotension reflects pre-operative down regulation of adrenergic receptors in the presence of excessive catecholamine secretion and requires asopressor support.

Biochemical cure should be confirmed by assay of 24-hour urinary VMA, 3-4 weeks after surgery. All the patients in the present series had normal urinary VMA levels on follow-up. The role of lifelong, annual urinary VMA, catecholamines measurements, to identify recurrent and or metachronous pheochromocytoma, cannot be underestimated $^{8,12}$.

\section{Conclusion:}

Pheochromocytoma is a rare catecholamine-secreting tumor derived from chromaffin cells. Because of excessive catecholamine secretion, pheochromocytomas may precipitate life-threatening HT. Biochemical analysis of urine for elevated levels of VMA proves diagnosis in majority. With the advent of CT scan and sonography, the localization of the tumor has become an easy task and nuclear scintigraphy is rarely required for this purpose. Adrenalectomy is a meticulous surgical exercise and requires team effort. With an adequate pharmacologically controlled HT, the results of the surgery are excellent. If the diagnosis of a pheochromocytoma is overlooked, the consequences could be disastrous or fatal; however, if a pheochromocytoma is found, it is potentially curable.

\section{Referencès:}

1. Sheps SG, Jiang NS, Klee GG. Diagnostic evaluation of pheochromocytoma. Endocrinol Metab Clin North Am 1988; 17: 397-414.

2. Remine WH, Chong GC, Van Heerden JA, Sheps SG, Harrison EG Jr. Current management of pheochromocytoma. Ann Surg 1974; 179: 740-8.

3. Frankel F. Ein Fall Von Duppelsentegen vollig latent Verlanfen nebennier entumor und pell gleichseitiger nephritis 2. mit Veranderungen am circulalation sappart und retinitis. Virchows Arch (A) 1886; 103: 244.

4. Mayo CH. Paroxysmal hypertension with tumor of retroperitoneal nerve. JAMA. 1927; 89:1047-8.

5. Thomas JL, Bernardino ME, Samaan NA, Hickey RC. CT for pheochromocytoma. AJR Am J Roentgenol 1980; 135: 477-82.

6. Witteles RM, Kaplan EL, Roizen MF. Safe and costeffective preoperative preparation of patients with pheochromocytoma. Anesth Analg 2000; 91: 302-4.

7. Shapiro B, Gross MD. Endocrine crises. Pheochromocytoma. Crit Care Clin 1991;7: 1-21.

8. Bravo EL, Gifford RW Jr. Pheochromocytoma. Endocrinol Metab Clin North Am 1993; 22: 329-41.

9. Beard CM, Sheps SG, Kurland LT, Carney JA, Lie JT. Occurrence of pheochromocytoma in Rochester, Minnesota, 1950 through 1979. Mayo Clin Proc 1983; 58: 802-4.

10. Neumann HP, Berger DP, Sigmund G, Blum U, Schmidt D, Parmer RJ et al. Pheochromocytomas, multiple endocrine neoplasia type 2, and von Hippel- Lindau disease. N Engl J Med 1993; 329: 1531-8.

11. Webb TA, Sheps SG, Carney JA. Differences between sporadic pheochromocytoma and pheochromocytoma in multiple endocrine neoplasia, type 2. Am J Surg Pathol 1980; 4: 121-6.

12. Gifford RW Jr, Kvale WF, Maher FT, Roth GM, Priestly JT. Clinical features, diagnosis and treatment of pheochromocytoma: a review of 76 cases. Mayo Clin Proc 1964; 39: 281-302.

13. Lenders JW, Keiser HR, Goldstein DS, Willemsen JJ, Friberg P, Jacobs MC et al. Plasma metanephrines in the diagnosis of pheochromocytoma. Ann Intern Med 1995; 123: 101-9.

14. Eisenhofer G, Lenders JW, Linehan WM, Walther MM, Goldstein DS, Keiser HR. Plasma normetanephrine and metanephrine for detecting pheochromocytoma in von Hippel-Lindau disease and multiple endocrine neoplasia type 2. N Engl J Med 1999; 340: 1872-9.

15. Welch TJ, Sheedy PF 2nd, van Heerden JA, Sheps SG, Hattery RR, Stephens DH. Pheochromocytoma: value of computed tomography. Radiology 1983; 148:501-3.

16. Modlin IM, Farndon JR, Shepherd A, Johnston ID, Kennedy TL, Montgomery DA et al. Pheochromocytomas in 72 patients: clinical and diagnostic features, treatment and long term results. Br J Surg 1979; 66: 456-65.

17. Sheps SG, Jiang NS, Klee GG, van Heerden JA. Recent developments in the diagnosis and treatment of pheochromocytoma. Mayo Clin Proc 1990; 65: 88-95.

18. Samaan NA, Hickey RC, Shutts PE. Diagnosis, localization, and management of pheochromocytoma. Pitfalls and followup in 41 patients. Cancer 1988; 62: 2451-60. 
19. Bravo EL, Gifford RW Jr: Current concepts. Pheochromocytoma: diagnosis, localization and management. N Engl J Med 1984; 311: 1298-303.

20. Hull CJ. Pheochromocytoma. Diagnosis, preoperative preparation and anesthetic management. Br J Anaesth 1986; 58: 1453-68.

21. Pullerits J, Ein S, Balfe JW. Anesthesia for pheochromocytoma. Can J Anaesth 1988; 35: 526-34.

22. Kinney MA, Warner ME, van Heerden JA, Horlocker TT, Young WF Jr, Schroeder DR et al. Perianesthetic risks and outcomes of pheochromocytoma and paraganglioma resection. Anesth Analg 2000; 91:1118-23.

23. Bravo E, Fouad-Tarazi F, Rossi G, Imamura M, Lin WW, Madkour MA et al. A reevaluation of the hemodynamics of pheochromocytoma. Hypertension 1990; 15:128-31.
24. van Heerden JA, Richard TS. Adrenalectomy, In: Baker RJ, Fischer JE, editors. Mastery of Surgery. $4^{\text {th }}$ ed. Philadelphia Lippincott Williams and Wilkins; 2001. p 543-51.

25. Thompson GB, Grant CS, van Heerden JA, Schlinkert RT, Young WF Jr, Farley DR et al. Laparoscopic versus open posterior adrenalectomy: a case-control study of 100 patients. Surgery 1997; 122:1132-6.

26. Shen WT, Lim RC, Siperstein AE, Clark OH, Schecter WP, Hunt TK et al. Laparoscopic versus open posterior adrenalectomy for treatment of primary hyperaldosteronism. Arch Surg 1999; 134: 628-31.

27. Prys-Roberts C. Pheochromocytoma - recent progress in its management. Br J Anaesth 2000; 85: 44-57. 